\title{
Potential Therapeutical Contributions of the Endocannabinoid System towards Aging and Alzheimer's Disease
}

\author{
Amandine E. Bonnet ${ }^{1}$, Yannick Marchalant ${ }^{2 *}$ \\ ${ }^{1}$ CNRS, NICN UMR 7259 Aix-Marseille University, 13344 Marseille, France. \\ ${ }^{2}$ Department of Psychology/Neuroscience program, Central Michigan University, MI 48859, USA
}

[Received June 1, 2015; Revised June 17, 2015; Accepted June 17, 2015]

\begin{abstract}
Aging can lead to decline in cognition, notably due to neurodegenerative processes overwhelming the brain over time. As people live longer, numerous concerns are rightfully raised toward long-term slowly incapacitating diseases with no cure, such as Alzheimer's disease. Since the early 2000's, the role of neuroinflammation has been scrutinized for its potential role in the development of diverse neurodegenerative diseases notably because of its slow onset and chronic nature in aging. Despite the lack of success yet, treatment of chronic neuroinflammation could help alleviate process implicated in neurodegenerative disease. A growing number of studies including our own have aimed at the endocannabinoid system and unfolded unique effects of this system on neuroinflammation, neurogenesis and hallmarks of Alzheimer's disease and made it a reasonable target in the context of normal and pathological brain aging.
\end{abstract}

Key words: Cannabinoids, Neuroinflammation, Neurogenesis, Aging, Alzheimer's disease

\begin{abstract}
Alzheimer's disease (AD) is the most common neurodegenerative disease and accounts for the majority of diagnosed dementia after age 60. It is estimated to currently affect between 20 and 30 million people worldwide with an incidence of the disease between 3 and $30 \%$ over the age of 60 [1]. As life expectancy increases, the prevalence of $\mathrm{AD}$ and its burden on healthcare is very likely to increase dramatically in the next few decades. Currently available drugs do not reverse or stop the progression of the disease, but only relieve certain cognitive symptoms and thus provide no cure for this growing health and economic concern.
\end{abstract}

\section{Alzheimer's disease \\ The disease is characterized by a slow but progressive loss of cognitive functions associated with neurodegeneration, as well as an important neuroinflammation [2]. More}

classically, AD is described mainly by two post-mortem histological diagnostic features that are extracellular amyloid $\beta$ protein (A $\beta)$ deposition and Tau hyperphosphorylation forming intracellular neurofibrillary tangles (NFT) [3-5]. Mutations in the genes coding for amyloid precursor protein $(A P P)$, presenilin-1 or -2 (PSEN1, PSEN2) have been identified as implicated in familial forms of $\mathrm{AD}$ and are known to favour the production of different $A \beta$ oligomeric assemblies and amyloid plaques in various region of the brain, notably the hippocampus, cortex and amygdala. This broadly accepted hypothesis, known as the amyloid cascade, states that the cause of $\mathrm{AD}$ pathophysiology is the massive production of $A \beta$ following cleavage of the APP by $\beta$-secretase and $\gamma$-secretase complex successively [6]. It also implies that all other hallmarks (inflammation and Tau hyperphosphorylation notably) are direct consequences of $A \beta$ exacerbated production. Nonetheless 
Tau proteins when hyperphosphorylated can form NFT that in turn impair intra-neuronal communication [7] and lead directly to cell death [5]. Although the amyloid cascade hypothesis is strongly supported, particularly in the familial forms of the disease that account for less than 5 per cent of all cases, increasing evidence suggests that the evolution/causes of the sporadic forms of the disease are different from the familial ones [8].

Indeed, another important feature of AD's pathology is the presence of a chronic inflammatory component. Several reviews over the last decade have extensively summarized those events [2,9]. If inflammatory processes are well known to accompany tissue damage in many neurodegenerative diseases as Parkinson's [10] or amyotrophic lateral sclerosis [11], AD's progression seems to be tightly linked to chronic inflammation. In fact, strong epidemiological evidence suggests inflammatory processes as partly responsible for the development of AD. For example, long-term use of non-steroidal antiinflammatory drugs (NSAID) lowers the prevalence of $\mathrm{AD}$ by $30-60 \%$ [12-14]. Furthermore, biochemical analysis of $\mathrm{AD}$ brains revealed elevated levels of proinflammatory cytokines such as IL-1, IL-6, TNF- $\alpha$ or $\mathrm{S} 100 \beta[2,15]$. On an histological point of view, gliosis (astrocytosis as well as microgliosis) is prominent and most plaques are surrounded by activated astrocytes and/or invaded by activated microglia [16,17]. A lot of the studies have focused on microglial cells, but it is now clear that microglial cells are assisted by astrocytes and endothelial cells [18] to maintain a chronic inflammatory state of the brain. This long lasting process (probably established over decades in the human brain) induces a chronic "stress" on neurons and affects their normal range of functioning. It has been clearly established that cell cycle proteins are activated [19], reactive oxygen species produced [19], mitochondrial function reduced [21] and denditric/axonal transport impaired [20].

Although numerous studies have validated inflammatory mediators or the brain's immune system in $\mathrm{AD}$, the precise role of inflammatory processes in the disease pathophysiology is still highly controversial (from beneficial to possibly triggering $\mathrm{AD}[21,22]$. As mentioned above, McGeer and coll. provided first support for a key role of inflammation in AD through a metaanalysis of 17 epidemiological studies, indicating that NSAIDs might decrease the risk of AD [12]. This has been followed by other epidemiological studies reporting that elevated levels of inflammatory factors (such as IL-6 and C-reactive protein notably) could be found in the plasma of $\mathrm{AD}$ patients long before clinical onset of the disease $[23,24]$. Moreover, diagnosis of dementia was more likely to be done during infection episodes [25]. Following such evidence, clinical trials however failed to show a beneficial effect of anti-inflammatory drugs in patients with symptomatic $\mathrm{AD}$ or mild cognitive impairment [26,27]. Based on the assumption that treatment needed to be timely, extended treatment of asymptomatic individuals with naproxen reduced the incidence of $\mathrm{AD}$, supporting a benefit when NSAIDs are administered in early asymptomatic phases of the disease [28]. Moreover, some patients with high plaque burden exhibit no dementia [29] and also demonstrate almost no evidence of neuroinflammation or neurodegeneration [30]. This actually is in accordance with observations made in several transgenic mouse models of $\mathrm{AD}$ often devoid of strong neuroinflammatory response or neurodegeneration [31]. Finally, studies using noninvasive brain imaging (MRI or PET) revealed that decrease in cognition performance in patients with $\mathrm{AD}$ is rather correlated with increased microglial activation, than with $A \beta$ load $[32,33]$.

On a cellular point of view, microglia is commonly accepted as recruited to clear $A \beta$ aggregates even if ablation of microglia in an AD mouse model wasn't found to change disease progression $[34,35]$. On the other end, microglia might also be primarily recruited to clear debris from neurons and neurites within plaques [36], $\mathrm{A} \beta$ aggregates included in the process. Finally, aged microglia may become senescent and its response nonappropriate in normal/pathological conditions [37], potentially explaining the role of inflammation early in the pathogenesis of $\mathrm{AD}$. In particular, its hyper-active state and sustained secretion of pro-inflammatory elements may lead to inefficient clearance of degenerating cells, leading to an overall toxic microenvironment prone to further degeneration and aggregate of proteins in the extracellular space.

Overall, it seems clear that neuroinflammation plays an important role in $\mathrm{AD}$ and that it may even influence disease progression very early on, especially as $\mathrm{AD}$ is diagnosed rather late while the mechanisms leading to neurodegeneration are already in motion probably decades before. To support this assumption, recent work from Knuesel's laboratory showed that chronic inflammation caused by viral infection with PolyI:C during the foetal period of non-transgenic animals can lead to very early changes in APP cleavage suggesting that neuroinflammation could trigger AD-like pathology in those animals [38].

\section{Cannabinoids}

The field of cannabinoid research has flourished over the past decades and have brought to light numerous functions of this system in normal and pathological conditions. So far two types of cannabinoid receptors have been identified, CB1 and CB2 [39,40]. Nonetheless other receptors are responsive to cannabinoids compounds: transient receptor potential vannilloid-1 (TRPV1), 
peroxisome proliferator-activated receptors $\alpha$ and $\beta$ (PPAR $\alpha$, PPAR $\beta$, see [41] for review). Discovery of cannabinoid receptors $(\mathrm{CBr})$ lead to the finding of endogenous agonists for these receptors called endocannabinoids (EC). In the central nervous system (CNS), CB1 is overwhelmingly represented over CB2, and the most abundant $\mathrm{G}$ protein-coupled receptors in the brain. CB1 is found in neurons and glial cells and particularly abundant in cortical regions, the hippocampus, cerebellum and basal ganglia [42]. It regulates numerous cerebral functions ranging from pain perception, motor control and feeding to emotion and memory processes. CB2 on the other end may be restricted to microglia [43] or neurons in the brainstem [44] and cerebellum [45]. Endocannabinoids are mostly derived from arachidonic acid, arachidonoylethanolamide (anandamide), and 2-arachidonoyl glycerol (2-AG), synthesized on-demand post-synaptically and released following calcium influx [46]. These EC in combination with the two known $\mathrm{CBr}$ constitute the endocannabinoid system (ECS). Deactivation of EC is rapid and due to enzymatic degradation in the synaptic cleft or reuptake [47]. The ECS is thought to be a neuromodulator [48] and an immunomodulator [49]. Cannabinoids demonstrated neuroprotective properties in numerous experimental conditions, some been or currently evaluated in various diseases ranging from cancer to AIDS for their peripheral analgesic and immunosuppressive properties [50,51]. Moreover, their anti-inflammatory properties could prove beneficial in the treatment of multiple sclerosis, Parkinson's disease and AD [52-57].

\section{Cannabinoids and Alzheimer's disease}

A growing amount of evidence points out to the possible implication of the ECS in the regulation of events occurring during the course of AD progression, particularly on the regulation of amyloid clearance and inflammation. Post-mortem analysis of AD brains demonstrated changes in the expression of CB1 but those remains still unclear. Some authors witnesses reduction of $\mathrm{CB} 1$ expression in cortical areas [58,59], a finding that is similar to that seen in aged rats [54], while others demonstrated no changes in the cortex or hippocampus of $\mathrm{AD}$ patients [60-63]. Moreover, CB1 levels do not correlates with $\mathrm{AD}$ markers or cognitive status [59]. On the other hand, CB2 increase has been clearly identified, notably located on microglia within the amyloid rich plaques [58,59] and Solas and coll. correlated level of CB2 receptors with A $\beta 42$ level and plaques [59]. Moreover, up-regulation of the fatty acid amide hydrolase occurs within plaques and might be responsible for increase in metabolites from anandamide degradation, such as arachidonic acid, and thus contribute to the inflammatory process seen in $\mathrm{AD}$ [60].

Several reports over the last two decades demonstrate the potential benefits from the modulation of the ECS over amyloid $\beta$ and Tau hyper-phosphorylation. In vitro studies demonstrated benefits of the use of different EC on cell survival following $A \beta$ exposition [64-67] and on Tau hyper-phosphorylation [68]. Morevover, $A \beta$ infusion in vivo (in rats and mice) is associated with gliosis and memory impairment, effects that can be reversed by diverse CB1, CB2 or mixed activation [58,69-73]. Two groups in Spain (De Ceballos and Ferrer's laboratories) have also demonstrated the cognitive benefits of chronic infusion of EC in transgenic mice model of AD [74-76]. Ferrer's group in particular also showed that chronic infusion of a CB1 or CB2 agonist could decrease Tau hyper-phosphorylation in APP/PS1 mice model of AD [74,75]. Nonetheless, most studies looking at the modulation of neuroinflammation using cannabinoids have mainly focused on $\mathrm{CB} 2$ receptors as they are mostly expressed on microglial cells. Studies mentioned earlier $[58,68,69,71]$ have observed reduction in microglial activation and pro-inflammatory cytokines following infusion of $A \beta$ in rodents. But as in many studies on $A D$ rodent models, those studies have difficulty pointing out if CB2 modulation benefits come from the reduction of neuroinflammatory processes per se or by the reduction of $A \beta$ activation of the neuroinflammatory system. Our lab did provide some potential clues on the role of the different $\mathrm{CB}$ receptors in this context. Indeed, our work demonstrated the anti-inflammatory potential using WIN$55,212-2$ chronically on chronic neuroinflammation in young and aged rats $[54,56,77]$ as well the neurogenic and cognitive effect of WIN-55,212-2 in aged animals [55]. Our data suggested that the anti-inflammmatory effect of WIN-55,212-2 could be due to its activity on TRPV1 receptors and its neurogenic effects linked to both CB1 and $\mathrm{CB} 2$ receptor.

\section{Conclusion}

Because of the complexity of pathological mechanisms involved in $\mathrm{AD}$ progression, a multi-drug approach seems to emerge as a better potential alternative as none of the available drug therapies are capable of altering the progression of the disease. The pleiotropic effects of cannabinoids, the numerous specific pharmacological tools to target its receptors and the growing number of pre-clinical effects on $\mathrm{AD}$ rodent models should finally raise the interest of the research community and be seen as a valuable alternative to slow disease progression or reduce some of the cognitive symptoms in AD. 


\section{References}

[1] Walsh DM, Selkoe DJ (2004). Deciphering the molecular basis of memory failure in Alzheimer's disease. Neuron, 44(1):181-93.

[2] Akiyama H, Barger S, Barnum S, Bradt B, Bauer J, Cole GM, et al. (2000). Inflammation and Alzheimer's disease. Neurobiol Aging, 21(3):383-421.

[3] Laferla FM, Green KN, Oddo S (2007). Alzheimer's disease, 8(July):499-509.

[4] Walsh DM, Selkoe DJ. (2007). A beta oligomers - a decade of discovery. J Neurochem. 101(5):1172-84.

[5] Kuret J, Chirita CN, Congdon EE, Kannanayakal T, Li G, Necula M, et al. (2005). Pathways of tau fibrillization. Biochim Biophys Acta, 1739(2-3):167-78.

[6] Haass C, Selkoe DJ (2007). Soluble protein oligomers in neurodegeneration: lessons from the Alzheimer's amyloid beta-peptide. Nat Rev Mol Cell Biol, 8(2):101-12.

[7] Ballatore C, Lee VM-Y, Trojanowski JQ (2007). Taumediated neurodegeneration in Alzheimer's disease and related disorders. Nat Rev Neurosci, 8(9):663-72.

[8] Herrup K (2010). Reimagining Alzheimer's Disease--An Age-Based Hypothesis. J Neurosci, 30(50):16755-62.

[9] Glass CK, Saijo K, Winner B, Marchetto MC, Gage FH. (2010). Mechanisms underlying inflammation in neurodegeneration. Cell. 140(6):918-34.

[10] McGeer PL, Yasojima K, McGeer EG (2002). Association of interleukin-1 beta polymorphisms with idiopathic Parkinson's disease. Neurosci Lett, 326(1):679.

[11] McGeer PL (2001). COX-2 and ALS. Amyotroph Lateral Scler Other Motor Neuron Disord, 2(3):121-2.

[12] McGeer PL, Schulzer M, McGeer EG (1996). Arthritis and anti-inflammatory agents as possible protective factors for Alzheimer's disease: a review of 17 epidemiologic studies. Neurology, 47(2):425-32.

[13] Vlad SC, Miller DR, Kowall NW, Felson DT (2008). Protective effects of NSAIDs on the development of Alzheimer disease. Neurology, 70(19):1672-7.

[14] Stewart WF, Kawas C, Corrada M, Metter EJ (1997). Risk of Alzheimer's disease and duration of NSAID use. Neurology, 48(3):626-32.

[15] Griffin WS, Sheng JG, Royston MC, Gentleman SM, McKenzie JE, Graham DI, et al. (1998). Glial-neuronal interactions in Alzheimer's disease: the potential role of a "cytokine cycle" in disease progression. Brain Pathol, 8(1):65-72.

[16] McGeer PL, Akiyama H, Kawamata T, Yamada T, Walker DG, Ishii T (1992). Immunohistochemical localization of beta-amyloid precursor protein sequences in Alzheimer and normal brain tissue by light and electron microscopy. J Neurosci Res, 31(3):428-42.

[17] Heneka MT, O’Banion MK (2007). Inflammatory processes in Alzheimer's disease. J Neuroimmunol, 184(1-2):69-91.

[18] Giri R, Selvaraj S, Miller CA, Hofman F, Yan SD, Stern D, et al. (2002). Effect of endothelial cell polarity on betaamyloid-induced migration of monocytes across normal and AD endothelium. Am J Physiol Cell Physiol, 283(3):C895-904.

[19] Fuller S, Münch G, Steele M (2009). Activated astrocytes: a therapeutic target in Alzheimer's disease? Expert Rev Neurother, 9(11):1585-94.

[20] Wu Q, Combs C, Cannady SB, Geldmacher DS, Herrup K (2000). Beta-amyloid activated microglia induce cell cycling and cell death in cultured cortical neurons. Neurobiol Aging, 21(6):797-806.

[21] Wyss-Coray $\mathrm{T}$ (2006). Inflammation in Alzheimer disease: driving force, bystander or beneficial response? Nat Med, 12(9):1005-15.

[22] Chakrabarty P, Li A, Ceballos-Diaz C, Eddy JA, Funk CC, Moore B, et al. (2015), IL-10 alters immunoproteostasis in APP mice, increasing plaque burden and worsening cognitive behavior. Neuron, 85(3):519-33.

[23] Schmidt R, Schmidt H, Curb JD, Masaki K, White LR, Launer LJ (2002). Early inflammation and dementia: a 25year follow-up of the Honolulu-Asia Aging Study. Ann Neurol, 52(2):168-74.

[24] Engelhart MJ, Geerlings MI, Meijer J, Kiliaan A, Ruitenberg A, van Swieten JC, et al. (2004). Inflammatory proteins in plasma and the risk of dementia: the rotterdam study. Arch Neurol, 61(5):668-72.

[25] Dunn N, Mullee M, Perry VH, Holmes C (2005). Association between dementia and infectious disease: evidence from a case-control study. Alzheimer Dis Assoc Disord, 19(2):91-4.

[26] Aisen PS, Schafer KA, Grundman M, Pfeiffer E, Sano M, Davis KL, et al. (2003). Effects of rofecoxib or naproxen vs placebo on Alzheimer disease progression: a randomized controlled trial. JAMA, 289(21):2819-26.

[27] Thal LJ, Ferris SH, Kirby L, Block GA, Lines CR, Yuen E, et al. (2005). A randomized, double-blind, study of rofecoxib in patients with mild cognitive impairment. Neuropsychopharmacology, 30(6):1204-15.

[28] Breitner JC, Baker LD, Montine TJ, Meinert CL, Lyketsos $\mathrm{CG}$, Ashe $\mathrm{KH}$, et al. (2011). Extended results of the Alzheimer's disease anti-inflammatory prevention trial. Alzheimers Dement, 7(4):402-11.

[29] Crystal H, Dickson D, Fuld P, Masur D, Scott R, Mehler M, et al. (1988). Clinico-pathologic studies in dementia: nondemented subjects with pathologically confirmed Alzheimer's disease. Neurology, 38(11):1682-7.

[30] Lue LF, Brachova L, Civin WH, Rogers J (1996). Inflammation, A beta deposition, and neurofibrillary tangle formation as correlates of Alzheimer's disease neurodegeneration. $\mathrm{J}$ Neuropathol Exp Neurol, 55(10):1083-8.

[31] Schwab C, Hosokawa M, McGeer PL (2004). Transgenic mice overexpressing amyloid beta protein are an incomplete model of Alzheimer disease. Exp Neurol, 188(1):52-64.

[32] Cagnin A, Brooks DJ, Kennedy AM, Gunn RN, Myers R, Turkheimer FE, et al. (2001). In-vivo measurement of activated microglia in dementia. Lancet, 358(9280):4617.

[33] Yokokura M, Mori N, Yagi S, Yoshikawa E, Kikuchi M, Yoshihara Y, et al. (2011). In vivo changes in microglial 
activation and amyloid deposits in brain regions with hypometabolism in Alzheimer's disease. Eur J Nucl Med Mol Imaging, 38(2):343-51.

[34] Lee CYD, Landreth GE. (2010). The role of microglia in amyloid clearance from the AD brain. J Neural Transm, 117(8):949-60.

[35] Grathwohl SA, Kälin RE, Bolmont T, Prokop S, Winkelmann G, Kaeser SA, et al. (2009). Formation and maintenance of Alzheimer's disease beta-amyloid plaques in the absence of microglia. Nat Neurosci, 12(11):13613.

[36] Sheng JG, Mrak RE, Griffin WS (1997). Neuritic plaque evolution in Alzheimer's disease is accompanied by transition of activated microglia from primed to enlarged to phagocytic forms. Acta Neuropathol, 94(1):1-5.

[37] Streit WJ (2006). Microglial senescence: does the brain's immune system have an expiration date? Trends Neurosci, 29(9):506-10.

[38] Krstic D, Madhusudan A, Doehner J, Vogel P, Notter T, Imhof C, et al. (2012). Systemic immune challenges trigger and drive Alzheimer-like neuropathology in mice. J Neuroinflammation, 9(1):151.

[39] Matsuda LA, Lolait SJ, Brownstein MJ, Young AC, Bonner TI (1990). Structure of a cannabinoid receptor and functional expression of the cloned cDNA. Nature, 346(6284):561-4.

[40] Munro S, Thomas KL, Abu-Shaar M (1993). Molecular characterization of a peripheral receptor for cannabinoids. Nature, 365(6441):61-5.

[41] Pertwee RG (2010). Receptors and channels targeted by synthetic cannabinoid receptor agonists and antagonists. Curr Med Chem, 17(14):1360-81.

[42] Herkenham M, Groen BG, Lynn AB, De Costa BR, Richfield EK (1991). Neuronal localization of cannabinoid receptors and second messengers in mutant mouse cerebellum. Brain Res, 552(2):301-10.

[43] Núñez E, Benito C, Pazos MR, Barbachano A, Fajardo O, González S, et al. (2004). Cannabinoid CB2 receptors are expressed by perivascular microglial cells in the human brain: an immunohistochemical study. Synapse, 53(4):208-13.

[44] Van Sickle MD, Duncan M, Kingsley PJ, Mouihate A, Urbani P, Mackie K, et al. (2005). Identification and functional characterization of brainstem cannabinoid CB2 receptors. Science. 310(5746):329-32.

[45] Ashton JC, Friberg D, Darlington CL, Smith PF. (2006). Expression of the cannabinoid $\mathrm{CB} 2$ receptor in the rat cerebellum: an immunohistochemical study. Neurosci Lett. 396(2):113-6.

[46] Bisogno T, Ligresti A, Di Marzo V. (2005). The endocannabinoid signalling system: biochemical aspects. Pharmacol Biochem Behav. 81(2):224-38.

[47] Piomelli D. (2003). The molecular logic of endocannabinoid signalling. Nat Rev Neurosci. 4(11):873-84.

[48] Vaughan CW, Christie MJ. (2005). Retrograde signalling by endocannabinoids. Handb Exp Pharmacol. (168):36783.
[49] Klein TW (2005). Cannabinoid-based drugs as antiinflammatory therapeutics. Nat Rev Immunol, 5(5):40011.

[50] Prentiss D, Power R, Balmas G, Tzuang G, Israelski DM (2004). Patterns of marijuana use among patients with HIV/AIDS followed in a public health care setting. J Acquir Immune Defic Syndr, 35(1):38-45.

[51] Walsh D, Nelson KA, Mahmoud FA (2003). Established and potential therapeutic applications of cannabinoids in oncology. Support Care Cancer, 11(3):137-43.

[52] Maresz K, Pryce G, Ponomarev ED, Marsicano G, Croxford JL, Shriver LP, et al. (2007). Direct suppression of CNS autoimmune inflammation via the cannabinoid receptor $\mathrm{CB} 1$ on neurons and $\mathrm{CB} 2$ on autoreactive $\mathrm{T}$ cells. Nat Med, 13(4):492-7.

[53] Eljaschewitsch E, Witting A, Mawrin C, Lee T, Schmidt PM, Wolf S, et al. (2006). The endocannabinoid anandamide protects neurons during CNS inflammation by induction of MKP-1 in microglial cells. Neuron, 49(1):67-79.

[54] Marchalant Y, Cerbai F, Brothers HM, Wenk GL (2008). Cannabinoid receptor stimulation is anti-inflammatory and improves memory in old rats. Neurobiol Aging, 29(12):1894-901.

[55] Marchalant Y, Brothers HM, Wenk GL (2009). Cannabinoid agonist WIN-55,212-2 partially restores neurogenesis in the aged rat brain. Mol Psychiatry, 14(12):1068-9.

[56] Marchalant Y, Brothers HM, Norman GJ, Karelina K, DeVries a. C, Wenk GL (2009). Cannabinoids attenuate the effects of aging upon neuroinflammation and neurogenesis. Neurobiol Dis, 34(2):300-7.

[57] Marchalant Y, Rosi S, Wenk GL (2007). Antiinflammatory property of the cannabinoid agonist WIN55212-2 in a rodent model of chronic brain inflammation. Neuroscience, 144(4):1516-22.

[58] Ramírez BG, Blázquez C, Gómez del Pulgar T, Guzmán M, de Ceballos ML (2005). Prevention of Alzheimer's disease pathology by cannabinoids: neuroprotection mediated by blockade of microglial activation. J Neurosci, 25(8):1904-13.

[59] Solas M, Francis PT, Franco R, Ramirez MJ (2013). CB2 receptor and amyloid pathology in frontal cortex of Alzheimer's disease patients. Neurobiol Aging, 34(3):805-8.

[60] Benito C, Núñez E, Tolón RM, Carrier EJ, Rábano A, Hillard CJ, et al. (2003). Cannabinoid CB2 receptors and fatty acid amide hydrolase are selectively overexpressed in neuritic plaque-associated glia in Alzheimer's disease brains. J Neurosci, 23(35):11136-41.

[61] Lee JH, Agacinski G, Williams JH, Wilcock GK, Esiri MM, Francis PT, et al. (2010). Intact cannabinoid CB1 receptors in the Alzheimer's disease cortex. Neurochem Int, 57(8):985-9.

[62] Mulder J, Zilberter M, Pasquaré SJ, Alpár A, Schulte G, Ferreira SG, et al. (2011). Molecular reorganization of endocannabinoid signalling in Alzheimer's disease. Brain, 134(Pt 4):1041-60.

[63] Ahmad R, Goffin K, Van den Stock J, De Winter F-L, Cleeren E, Bormans G, et al. (2014). In vivo type 1 
cannabinoid receptor availability in Alzheimer's disease. Eur Neuropsychopharmacol, 24(2):242-50.

[64] Milton NGN (2002). Anandamide and noladin ether prevent neurotoxicity of the human amyloid-beta peptide. Neurosci Lett, 332(2):127-30.

[65] Chen X, Zhang J, Chen C (2011). Endocannabinoid 2arachidonoylglycerol protects neurons against $\beta$-amyloid insults. Neuroscience, 178:159-68.

[66] Harvey BS, Ohlsson KS, Mååg JL V, Musgrave IF, Smid SD (2012). Contrasting protective effects of cannabinoids against oxidative stress and amyloid- $\beta$ evoked neurotoxicity in vitro. Neurotoxicology, 33(1):138-46.

[67] Janefjord E, Mååg JL V, Harvey BS, Smid SD (2014). Cannabinoid effects on $\beta$ amyloid fibril and aggregate formation, neuronal and microglial-activated neurotoxicity in vitro. Cell Mol Neurobiol, 34(1):31-42.

[68] Esposito G, De Filippis D, Steardo L, Scuderi C, Savani C, Cuomo V, et al. (2006). CB1 receptor selective activation inhibits beta-amyloid-induced iNOS protein expression in C6 cells and subsequently blunts tau protein hyperphosphorylation in co-cultured neurons. Neurosci Lett, 404(3):342-6.

[69] Sciences ML, Stelt M Van Der, Mazzola C, Esposito G, Matias I, Petrosino S, et al. (2006). Endocannabinoids and $\beta$-amyloid-induced neurotoxicity in vivo: effect of pharmacological elevation of endocannabinoid levels, 63:1410-24.

[70] Haghani M, Janahmadi M, Shabani M (2011). Protective effect of cannabinoid $\mathrm{CB} 1$ receptor activation against altered intrinsic repetitive firing properties induced by $\mathrm{A} \beta$ neurotoxicity. Neurosci Lett, 507(1):33-7.

[71] Wu J, Bie B, Yang H, Xu JJ, Brown DL, Naguib M (2013). Activation of the CB2 receptor system reverses amyloid-induced memory deficiency. Neurobiol Aging, 34(3):791-804.

[72] Martín-Moreno AM, Reigada D, Ramírez BG, Mechoulam R, Innamorato N, Cuadrado A, et al. (2011). Cannabidiol and other cannabinoids reduce microglial activation in vitro and in vivo: relevance to Alzheimer's disease. Mol Pharmacol, 79(6):964-73.

[73] Fakhfouri G, Ahmadiani A, Rahimian R, Grolla AA, Moradi F, Haeri A (2012). WIN55212-2 attenuates amyloid-beta-induced neuroinflammation in rats through activation of cannabinoid receptors and PPAR- $\gamma$ pathway. Neuropharmacology, 63(4):653-66.

[74] Aso E, Palomer E, Juvés S, Maldonado R, Muñoz FJ, Ferrer I (2012). CB1 agonist ACEA protects neurons and reduces the cognitive impairment of A $\beta P P / P S 1$ mice. $J$ Alzheimers Dis, 30(2):439-59.

[75] Aso E, Juvés S, Maldonado R, Ferrer I (2013). CB2 cannabinoid receptor agonist ameliorates Alzheimer-like phenotype in A $\beta P P / P S 1$ mice. J Alzheimers Dis, 35(4):847-58.

[76] Martín-Moreno AM, Brera B, Spuch C, Carro E, GarcíaGarcía L, Delgado M, et al. (2012). Prolonged oral cannabinoid administration prevents neuroinflammation, lowers $\beta$-amyloid levels and improves cognitive performance in Tg APP 2576 mice. J Neuroinflammation, 9:8.

[77] Marchalant Y, Rosi S, Wenk GL (2007). Antiinflammatory property of the cannabinoid agonist WIN$55212-2$ in a rodent model of chronic brain inflammation. Neuroscience, 144(4):1516-22. 